\title{
Effective pressure and treatment duration of high hydrostatic pressure to prepare melanoma vaccines
}

\author{
KAI LIU ${ }^{1}$, SHUAI YAN ${ }^{2}$, ZHANCHUAN MA $^{3}$ and BIN LIU ${ }^{1}$ \\ Departments of ${ }^{1}$ Hand and Foot Surgery and ${ }^{2}$ Operating Room; ${ }^{3}$ Institute of Immunology, \\ The First Hospital of Jilin University, Changchun, Jilin 130021, P.R. China
}

Received October 15, 2019; Accepted April 6, 2020

DOI: $10.3892 / \mathrm{ol} .2020 .11657$

\begin{abstract}
Current therapeutic methods for melanoma have numerous limitations, and thus the improvement of such treatment methods are essential. One possible option is the vaccination of autologous inactivated tumor cells. The primary indispensable principles of a cell-based melanoma vaccine include: i) Entire inactivation of melanoma cells; ii) retaining the immunogenicity of melanoma cells; and iii) adherence to laws and ethical guidelines. However, traditional methods for the production of the vaccine, such as ultrasonic, chemotherapeutics and freeze-thawing, have some juridical or therapeutic constraints. Therefore, the present study used high hydrostatic pressure (HHP) to inactivate malignant cells, and treated B16-F10 tumor cells with different pressures ( $\geq 50 \mathrm{MPa}$ ) and different durations ( $\geq 1 \mathrm{~min}$ ). It was identified that tumor cells in vitro lost their proliferative ability, but retained their immunogenicity following treatment. Furthermore, the vaccination of the melanoma cells significantly suppressed their oncogenesis. Collectively, the present results suggest that HHP treatment may be an economically viable and effective measure to develop a melanoma vaccine, when pressure was $\geq 200 \mathrm{MPa}$ and the treatment duration was $\geq 30 \mathrm{~min}$.
\end{abstract}

\section{Introduction}

Traditional treatment methods of human cancer types primarily include resection, chemotherapy or radiotherapy (1). Single or combination therapy can control local tumors and prolong the lifespan of the patient (2). However, these therapies have limitations, such as causing greater trauma and toxic side

Correspondence to: Professor Bin Liu, Department of Hand and Foot Surgery, The First Hospital of Jilin University, 1 Xinmin Street, Changchun, Jilin 130021, P.R. China

E-mail: liuk0504@163.com

Abbreviations: DC, dendritic cells; HHP, high hydrostatic pressure; $\mathrm{CFU}$, colony-forming units; DTH, delayed-type hypersensitivity

Key words: HHP, effective pressure, melanoma vaccine, treatment duration, immunogenicity effects on patients, which impact their long-lasting anti-cancer effects (3). Moreover, the recrudescence and metastasis of tumors cannot be fully controlled by traditional treatments (4).

Previous studies have reported that tumor occurrence is associated with the immune system in the human body $(5,6)$. Furthermore, immunotherapy of tumors has been promising, and multiple methods have been tested over the past few decades $(7,8)$. Previous studies on tumor immunotherapy have revealed the characteristics of immune system response related to cancer occurrence $(9,10)$, and some of these studies have involved the use of dendritic cells (DCs) (11). DCs connect the innate and adaptive immune systems by functioning as antigen-presenting cells, and have been used as tumor vaccines in several clinical experiments $(12,13)$. Furthermore, immunotherapy based on DCs has been reported to be safe and capable of inducing anti-tumor immunity (14).

The application of cancer vaccines has become an important procedure, and immunotherapy has been used for the standard treatment and continuous control of tumors (15). However, the immunoreactions triggered by these vaccines are inefficient due to a lacking number of lymphocytes (16). Therefore, it is important to develop novel types of vaccines that can activate the immune system to generate long-lasting immunity. It has been suggested that vaccines may induce a strong immune response and elicit immunological memory (15).

As for the preparation of vaccine, it has been proved that the immune response is induced by autologous cancer cells in the host, leading to a large number of tumor antigens produced by the immune system (17). Regardless of the final result, this type of vaccine includes the main principles of cell-based vaccines: i) Complete inactivation of tumor cells; ii) maintaining the immunogenicity of cells; and iii) adherence to the laws and ethical guidelines. Physical methods, such as freeze-thawing or ultrasonication, and chemotherapeutics for the inactivation of the tumor cells have certain restrictions, such as inadequate inactivation of cells and the addition of toxic impurities (18). Moreover, certain laws have forbidden the use of X-ray irradiation and lethal factors of toxic drugs in humans (19).

Treatment with high hydrostatic pressure (HHP) has helped overcome the aforementioned limitations $(20,21)$. Previous studies have reported the use of HHP as a disinfectant in the pharmaceutical and foodstuff industries (22-24), and thus microorganisms are killed without the use of radiation, heat 
or chemicals $(21,25)$. With regards to the applications of HHP in medicine, it has been utilized to disinfected the bone, while maintaining biomechanical stability (26), and has also been researched in Alzheimer's disease (27). Previous studies have investigated the application of HHP for the development of the bacterial vaccines (28) and its effect on lipoprotein particles (29). The effect of HHP on biological particles has been previously examined (21). It has been revealed that proteins cannot maintain their primary structures, and the tertiary and quaternary structures of proteins could be transformed by HHP (19). Moreover, biological enzymes may lose their abilities after HHP treatment (30). Furthermore, the conformation of DNA and lipid bilayers may undergo significant changes during HHP (31).

To study the effective pressure treatment durations $(1,5$, $10,30,60$ and $120 \mathrm{~min})$ and the effective pressures $(50,100$, 200, 300 and $500 \mathrm{MPa}$ ) of HHP to inactivate melanoma cells, B16 melanoma cells were subjected to different treatment conditions. In addition, cell death was examined over a culture period of $48 \mathrm{~h}$. A clonogenic assay was also performed to assess the proliferative abilities of the cells. Furthermore, HHP-treated cells were used in the mouse models to determine immunogenicity.

\section{Materials and methods}

Cell line and culture. The cell line used was luciferase-labeled B16 melanoma cells (B16-F10; Xenogen Corporation), and mycoplasma testing was performed for this cell line. Cells were cultivated with DMEM (HyClone; GE Healthcare Life Sciences), 10\% FBS (Gibco; Thermo Fisher Scientific, Inc.), $1 \%$ penicillin-streptomycin (Beijing Transgen Biotech Co., Ltd.) and 1\% L-glutamine (AMRESCO,LLC). Melanoma cells were cultivated under conditions of $100 \%$ relative humidity and $37^{\circ} \mathrm{C}$ in a $5 \% \mathrm{CO}_{2}$ atmosphere.

HHP treatment of cells. Cells were separated from the petri dish with $0.25 \%$ trypsin (HyClone; GE Healthcare Life Sciences). Then, cells were centrifuged $\left(1,500 \mathrm{x} g\right.$ at $4^{\circ} \mathrm{C}$ for $5 \mathrm{~min}$ ), rinsed (sterile PBS) and re-suspended in vitro. Soft-seal vacuum sterile plastic bags (Alibaba Group) were used to avert the leakage of cells during the treating processes (Fig. 1). The plastic bag was filled with a cell suspension of $3.2 \times 10^{7}$ melanoma cells and securely closed. Then, the plastic bag was placed into another soft plastic bag and a vacuum seal was created to avoid the air bubbles reducing the pressure during the HHP treatment. The plastic bags were placed in the pressure-autoclave of the equipment [cat. no. DH600-0.8X2 (9242); Dalong Goepe. (http://www.dalongyeya.com/)]. The pressure chamber was locked using the screwing flanges and the pressure was elevated with an electric pump. In the present study, the pressure of HHP used was $\geq 50 \mathrm{MPa}$ ( $1 \mathrm{MPa}=10$ bar=9.86923 atm=145.0377 psi). When the digital pressure sensor displayed the desired numerical value (50, $100,200,300$ and $500 \mathrm{MPa}$ ) the pump was suspended. The equipment held the pressure for the different required durations $(1,5,10,30,60$ and $120 \mathrm{~min})$. The pressure was detected continually using a digital pressure sensor. Then, the valve was opened slowly, and the pressure was gradually decompressed to atmospheric pressure.
Clonogenic assay. Following HHP treatment, $1 \times 10^{4}$ cells were cultured in the cell culture dishes for 14 days. Then, $0.25 \%$ methylene blue solution was used to stain the colonies in the dishes $\left(25^{\circ} \mathrm{C}\right.$ for $\left.10 \mathrm{~min}\right)$ and colonies were counted manually. The colony-forming units (CFU) results were compared with the numbers of colonies related to the untreated cells.

Immunization of mouse models. A total of 105 mice (C57BL/6 mice; female; age, 4-6 weeks; weight, $15.00 \pm 0.33 \mathrm{~g}$; Beijing Vital River) were raised in well-ventilated cages in these studies. Three mice were raised per cage. The mice were given a sterile special diet (white noodle $37 \%$, corn noodle $22 \%$, bran $17 \%$, soybean meal $13 \%$, fish meal $4 \%$, egg $1 \%$, yeast powder $1 \%$, bone meal $3 \%$, salt $1 \%$ and cod liver oil $1 \%$ ) and water. The animals could access to food and water ad libitum. The cages were kept under normal conditions for temperature $\left(23 \pm 3^{\circ} \mathrm{C}\right)$, humidity $(55 \pm 15 \%)$ and light (12/12 h light-dark cycles). All animal experiments were conducted according to the National Standard of the Care and Use of Laboratory Animals (32), and the study was approved by the Animal Ethics Committee of The First Hospital of Jilin University (Changchun, China; Approval no. 2019-0456).

Then, emulsification was performed using two $5 \mathrm{ml}$ glass syringes and a medical tee joint to mix the treated cell suspension with $1.5 \mathrm{ml}$ complete Freund's adjuvant (Sigma-Aldrich; Merck KGaA) for $30 \mathrm{~min}$. Subsequently, $100 \mu \mathrm{l}$ emulsified liquid was injected under the skin of the posterior neck of the mice. The injection was carried out at the same location three times, every 2 weeks. During the second and third injections, the same dosage Freund's incomplete adjuvant (Sigma-Aldrich; Merck KGaA) was used. The control group was injected with the same dose of emulsion of saline and the Freund's adjuvant (the first injection) or the Freund's incomplete adjuvant (the second and third injections). The health and behavior of the mice were monitored every day after the injection.

Detection of the immune effect. Thirty treatment groups and one control group ( $\mathrm{n}=3$ mice for each group) were prepared for this experiment. There were five treatment groups $(50,100$, $200,300$ and $500 \mathrm{MPa})$ at six treatment durations $(1,5,10,30$, 60 and $120 \mathrm{~min}$ ). All experiments were performed in triplicate. Seven days following the final injection, the delayed-type hypersensitivity (DTH) test was performed by subcutaneously injecting $5 \times 10^{6}$ melanoma cells, which were suspended in $70 \mu 1$ sterile PBS, into the palm of the hind paw of the mice. The same volume of PBS was injected into the other palm of the hind paw (the control group only received injections of saline). The swelling degree of the paws was measured after $24 \mathrm{~h}$ using a digital caliper (Iron Bridge Tools, Inc.).

The B16-F10 cell suspension was subcutaneously injected into the flank of the mice; the concentration of the suspension was $1 \times 10^{6} \mathrm{cells} / \mathrm{ml}$ and the volume was $0.1 \mathrm{ml}$. An electric razor was used to remove the hair of the flank to observe the apophysis of tumors. After the injection, the flank was observed every day to identify the tumors. After the tumors appeared, a digital caliper (Iron Bridge Tools, Inc.) was used to measure the length (L) and the width (W) of these subcutaneous tumors, which were measured every 2 days until day 14 following the subcutaneous injection. The maximum diameter exhibited by a single subcutaneous tumor was $9 \mathrm{~mm}$. The 


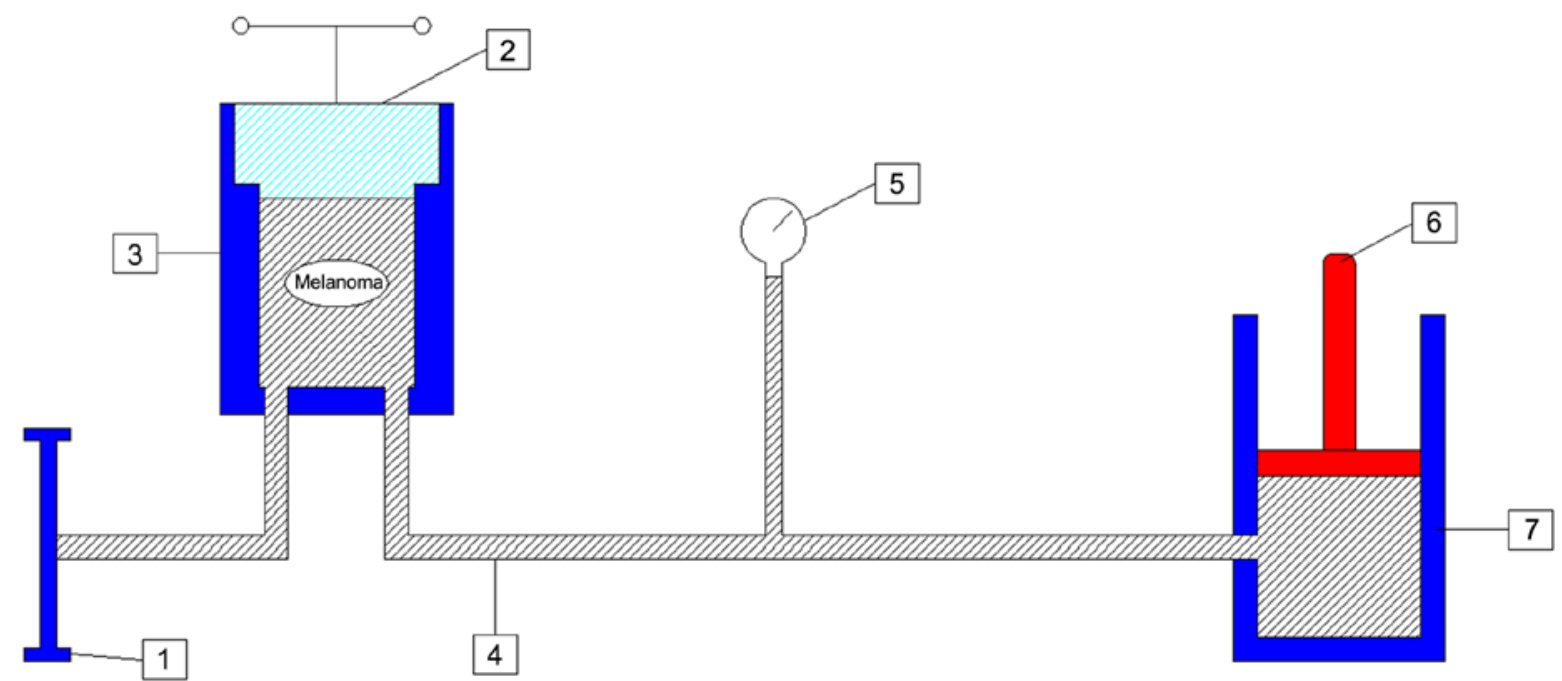

Figure 1. Schematic representation of the equipment required to induce high hydrostatic pressure. The equipment consists of the following assembly parts: 1 , Valve; 2 , flanged closure; 3 , pressure autoclave; 4 , pipeline filled with pressure transmitting media, the compound of the kerosene and the transformer oil; 5 , digital pressure sensor; 6 , the pump; and 7 , the reservoir.

volume of the tumor $(\mathrm{V})$ was calculated using a previously described formula (1): $\mathrm{V}=0.5 \times 2 \mathrm{~L} \mathrm{x} \mathrm{W}$.

Then, $0.4 \mathrm{ml}$ the concentration of $1 \times 10^{6}$ cells $/ \mathrm{ml}$ cell suspension was injected into the caudal vein. Five treatment groups and one control group ( $n=2$ mice for each group) were prepared for this experiment. The number of mice used in repeated experiments were the same. After 7 days of the injection, ketamine was used for anesthesia via intraperitoneal injection, at a concentration of $100 \mathrm{mg} / \mathrm{kg}$ (33). When the anesthetic took effect (the heart rate and breath of the mice were even, the muscles were relaxed, the limbs were not active), $15 \mathrm{mg} / \mathrm{ml}$ D-luciferin potassium salt (Shanghai Sciencelight Biology Science \& Technology Co., Ltd.) was injected via intraperitoneal injection, at a concentration of $10 \mathrm{mg} / \mathrm{kg}$. Then, mice were placed in the biofluorescence imager (IVIS Lumina XR; EMD Millipore) for fluorescence imaging, following the manufacturer's instructions, with the time of exposure at 1 min.

Mice were euthanized after the fluorescence imaging test via cervical dislocation under the same anesthesia procedure as aforementioned. The heart rate and respiration of mice stopped completely, and the nerve reflex disappeared. The following criteria for humane endpoints in oncological laboratory animals were implemented: The weight of the subcutaneous tumor was $<10 \%$ of the original weight of the animal; the average diameter of the tumor was $<20 \mathrm{~mm}$ in the adult mice; no ulcer, necrosis or infection emerged on the skin at the site of a tumor; no abdominal cavities of the mice were abnormally dilated and the mice did not have difficulty breathing or exhibit neuropsychiatric symptoms (34). No mice had any of these symptoms. The purpose of selecting and determining the humane endpoint was to accurately predict the end point of the experiment before the animals experienced unnecessary pain due to the experiment, to shorten the experiment time to the greatest extent and to avoid or reduce the pain and suffering caused to the animals in the later period of the experiment (34). A small number of the experimental animals in the present study exhibited slight abdominal distention.
Statistical analysis. All experiments were performed $\geq 3$ times. Data are presented as the mean \pm SD. Data were analyzed for statistical significance using SPSS version 21.0 software (IBM Corp.). The clonogenic assay, the DTH test and tumor growth curves were analyzed via one-way ANOVA, followed by Bonferroni's correction. $\mathrm{P}<0.05$ was considered to indicate a statistically significant difference.

\section{Results}

Clonogenic assay of HHP-treated cells. A clonogenic assay was performed to detect the CFU of the treated cells in vitro. Regardless of the treatment duration, the pressure of $50 \mathrm{MPa}$ did not significantly affect the proliferation of malignant cells. However, after treatment with $100 \mathrm{MPa}$ for $1 \mathrm{~min}$, the ability of colony-forming slightly declined. As the duration increased, the CFU began to decrease, and when the duration was $>30 \mathrm{~min}$, the percentage of CFU was notably decreased. Moreover, the CFU (\%) of cancer cells that were treated for $120 \mathrm{~min}$ under the pressure of $100 \mathrm{MPa}$ approached zero. In addition, it was demonstrated that all tumor cells treated with $\geq 200 \mathrm{MPa}$ for $\geq 30 \mathrm{~min}$ significantly lost their in vitro ability to form colonies $(\mathrm{P}<0.001)$ (Fig. 2A).

Immunogenicity of HHP-treated cells. The results of the DTH test indicated that groups with 300 and $500 \mathrm{MPa}$ had significant immune effects when the duration was $\geq 5$ min (Fig. 2B). Furthermore, group with $200 \mathrm{MPa}$ achieved the same significant result when the duration was $\geq 30 \mathrm{~min}$. It was revealed that almost all HHP-inactivated cells held the immunogenicity response, except the groups with 50 and $100 \mathrm{MPa}$ for $<60 \mathrm{~min}$.

Mouse models were also used to test the immunogenicity of HHP-treated cells. After the sixth day of the subcutaneous injection in the flank, subcutaneous tumors were observed in the majority of mice.

When the treatment duration was $1 \mathrm{~min}$, the group treated with $500 \mathrm{MPa}$ had a significantly different V compared with other groups at day 14 (Fig. $3 \mathrm{~A} ; \mathrm{P}<0.05$ ). When the duration 


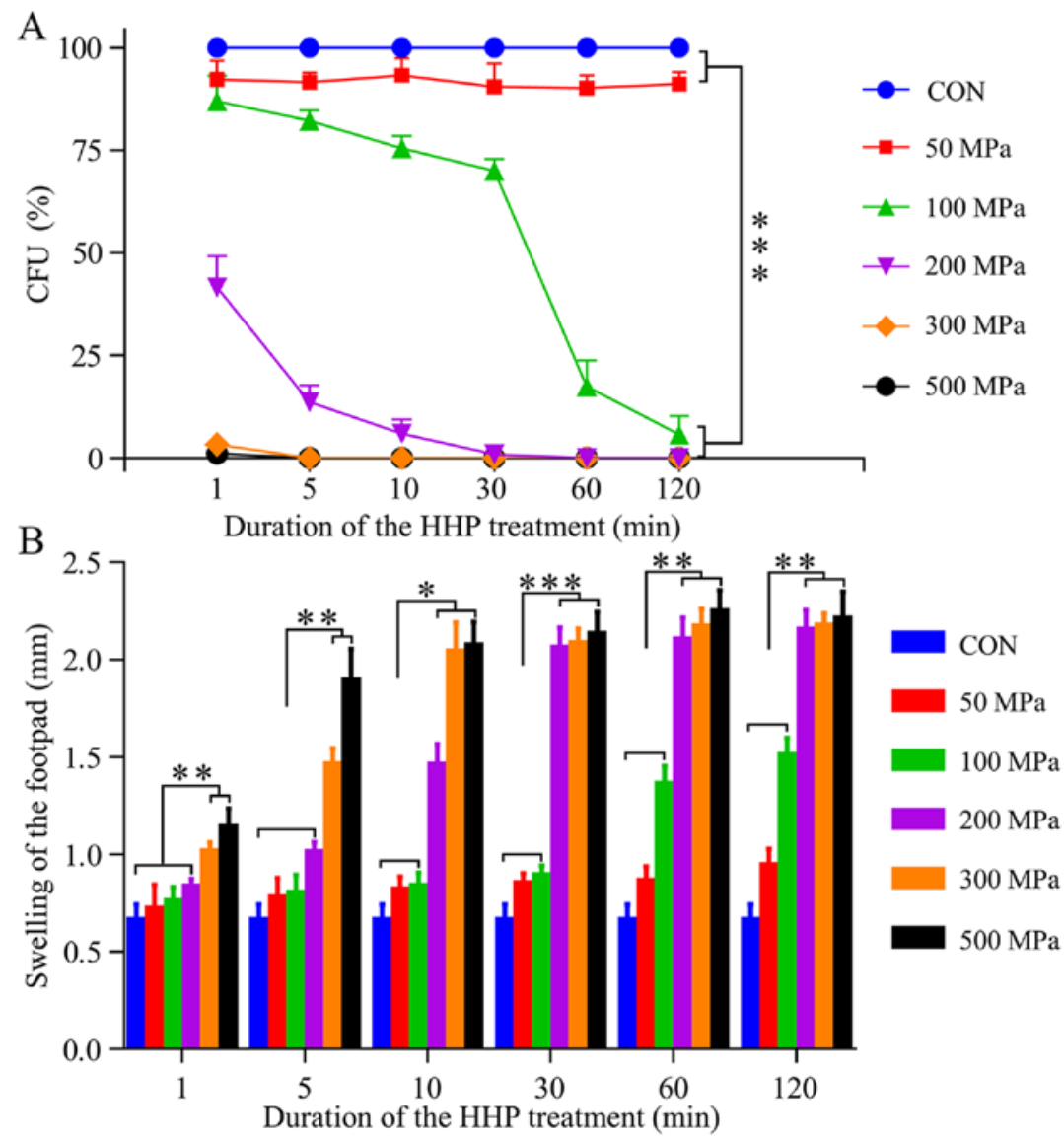

Figure 2. Clonogenic assay and detection of immune effect. (A) Colony-forming ability of tumor cells after HHP treatment. Data are presented as the percentage of the CFU, which was compared with the control group. (B) Results of the delayed-type hypersensitivity test. Each set of data was acquired from three independent tests and presented as the mean $\pm \mathrm{SD}$. $\mathrm{n}=3$. ${ }^{*} \mathrm{P}<0.05,{ }^{* *} \mathrm{P}<0.01,{ }^{* * * *} \mathrm{P}<0.001$. HHP, high hydrostatic pressure; CON, control; CFU, colony forming units.

of HHP was 5 min, the groups treated with 200, 300 and $500 \mathrm{MPa}$ had a significantly decreased $\mathrm{V}$ compared with other groups (Fig. 3B; $\mathrm{P}<0.01$ ). Furthermore, when the treatment duration was $10 \mathrm{~min}$, the groups treated with 200,300 and $500 \mathrm{MPa}$ also had a significantly decreased V compared with other groups at day 14 (Fig. 3C; $\mathrm{P}<0.01$ ). When the treatment duration was $\geq 30 \mathrm{~min}, 200,300$ and $500 \mathrm{MPa}$ groups had a significantly decreased immune effect compared with the other groups (Fig. 3D-F; P<0.001); however, there were no significant differences between these three groups $(P>0.05)$.

After 2 weeks of the injection, bioluminescence was investigated (Fig. 4). The immunofluorescence results suggested that a pressure of $\geq 200 \mathrm{MPa}$ could be used to develop a vaccine to suppress tumor growth, when the duration of pressure was $\geq 30 \mathrm{~min}$.

\section{Discussion}

A previous study reported the importance of the immune system for treating melanoma (35). Moreover, as a promising therapeutic method, an autologous malignant cell vaccine has been used to treat correlative tumors (36). A previous study suggested that inactivated cancer cells may be used as vaccines for malignant diseases (37). However, for their potential use as an anti-tumor treatment, it is important to inactivate the cancer cells (38). Moreover, cell inactivation should be in line with the three basic principles: i) Complete inactivation of tumor cells; ii) maintaining the immunogenicity of cells; and iii) adherence to the laws and ethical guidelines, and the immunogenicity of the inactivation cells and method of inactivation are directly associated with the treatment effect. Retaining immunogenicity is the most important process and the most significant challenge facing the development of autologous whole tumor cell-based vaccines (36). Furthermore, these vaccines possess qualities that targeted antigens do not, which can be identified prospectively, and they can deliver numerous tumor-associated antigens, which are highly expressed self-antigens. In contrast to neo-antigens, autologous whole tumor cell-based vaccines should only be able to activate the remaining low-affinity $\mathrm{T}$ cells and would have to break self-tolerance (36). Moreover, several additional methods have been developed to overcome these limitations, such as the addition of adjuvants, repeated vaccinations or co-stimulators (39). It has been reported that whether the inactivated cells are immunogenic or not depends on the inactivation methods of the cells, as well as the cell death-initiating stimulus (40). Furthermore, certain cell death inducers result in the exposure of immunogenic factors on the surface or the release of immunogenic signals into the extracellular fluid (41). In addition, the same anticancer agent can cause the release of signals from certain tumor types, which is due to the fact that this release requires the intervention of specific signal transduction pathways (40). 

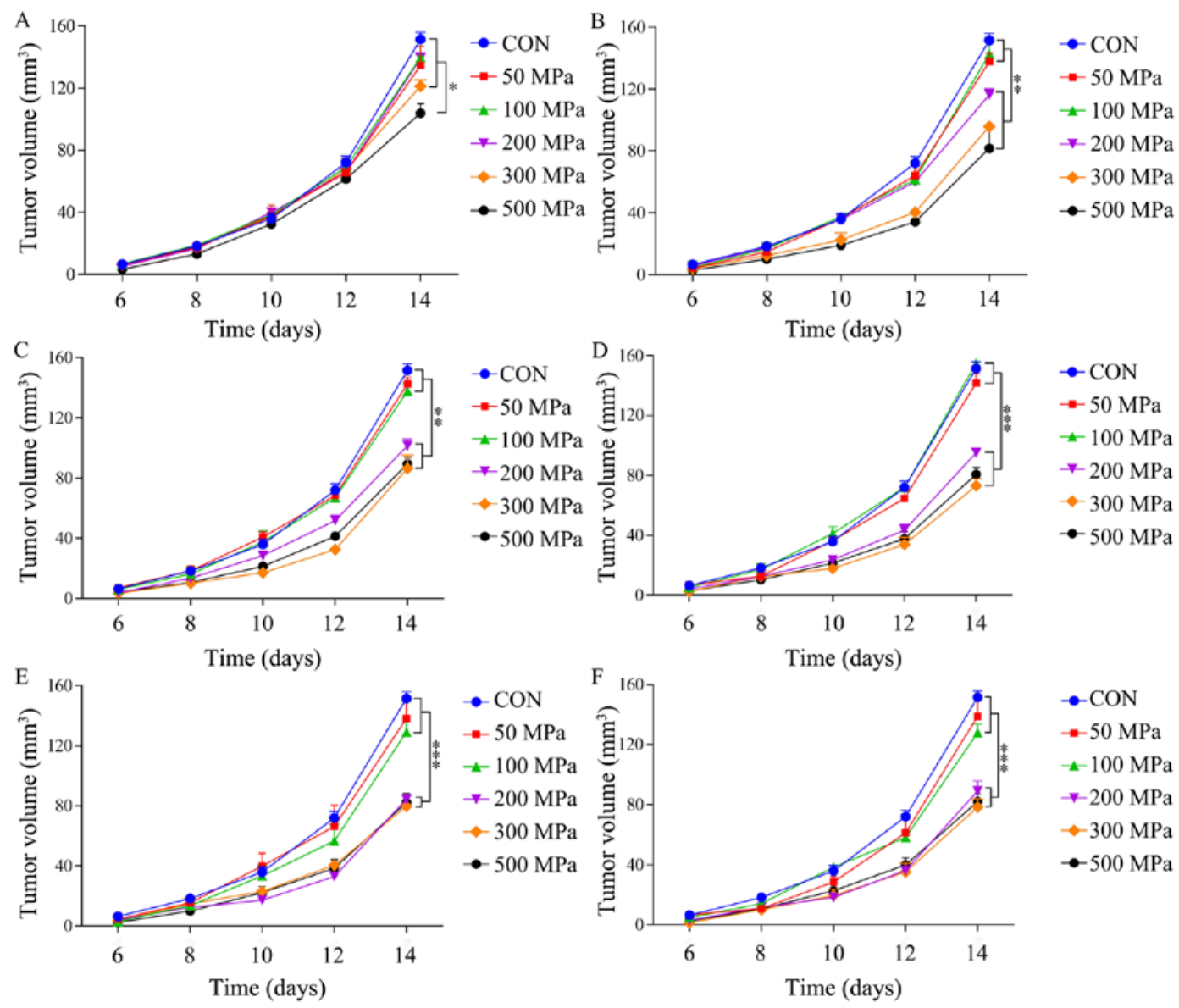

Figure 3. Volumes of subcutaneous tumors. (A) Treatment duration is $1 \mathrm{~min}$. (B) Treatment duration is $5 \mathrm{~min}$. (C) Treatment duration is $10 \mathrm{~min}$. (D) Treatment duration is $30 \mathrm{~min}$. (E) Treatment duration is $60 \mathrm{~min}$. (F) Treatment duration is $120 \mathrm{~min}$. The different colors of the graphs exhibited volumetric change of every group. Each set of data, which were acquired from three independent tests, were presented as the mean $\pm \mathrm{SD} . \mathrm{n}=3,{ }^{*} \mathrm{P}<0.05,{ }^{* *} \mathrm{P}<0.01,{ }^{* * *} \mathrm{P}<0.001$. CON, control.

Although HHP is known to denature proteins, it does not affect the covalent bonds, meaning the primary and secondary structures of the proteins are maintained, while their tertiary and quaternary structures are changed (42). A previous study showed that HHP-treated tumor cells affect the antigenic pool and DCs and HHP-killed tumor cells may induce $\mathrm{CD} 8^{+} \mathrm{T}$ cell-mediated responses (43). Moreover, HHP-treatment induces immunogenic tumor cell death, and the interaction between tumor cells killed with HHP and DC results in the phagocytosis of cancer cells and activation of DC (44). Thus, previous studies have suggested that the treatment of HHP fulfils the main requirements for a clinical vaccine, in that it inactivates tumor cells effectively, retains the immunogenicity of the cancer cells, had no intrinsic toxicity and complied with the requirements of the Good Manufacturing Practice (19). Furthermore, HHP-treatment is a simple and reproducible method (45). Therefore, this vaccination has advantages over other preparation methods such as radiation, freeze-thaw or heat treatment. Moreover, the primary aim of the present study was to investigate whether different durations and pressures affect the results of the vaccination.

When tumor cells were treated with different pressures for the different durations, the effects on tumor cell death and the structures of cellular elements were different (19). Necrotic cells induce inflammatory processes; however, apoptotic cells primarily cause anti-inflammatory reactions (46). In the present study, it was demonstrated that the treatment durations did not affect the viability of the tumor cells when the pressure was 50 or $100 \mathrm{MPa}$; the immune reactions induced by these cells were too low to affect the development of tumors. However, when the pressure was $\geq 200 \mathrm{MPa}$, it elicited a strong effect on cell viability. Moreover, when the pressure of HHP treatment was 100-300 MPa, the degeneration of protein was reversible; however, when the pressure was $\geq 300 \mathrm{MPa}$, the denaturation of protein was irreversible (47). It was also indicated that HHP treatment with $\geq 200 \mathrm{MPa}$ resulted in the death of tumor cells in the first $24 \mathrm{~h}$ of the culture, and none of these treated tumor cells could form new colonies.

The vaccination of whole cancer cells supplies a number of antigens to the immune system, and this could result in long-lasting anti-tumor immunity (19). A previous study has reported that serum antibodies could be released by vaccines of the treated cells (48). In the present study, the number of the specific $\mathrm{IgG}$ antibodies treated by the HHP treatment (pressure $\geq 200 \mathrm{MPa}$, duration $\geq 30 \mathrm{~min}$ ) was not decreased. Moreover, the repellent T-lymphocyte reaction, which was measured by the DTH response, was significantly increased. Thus, these results suggested that as the pressure increased and the duration prolonged, the immune effect of the melanoma cells could not increase significantly, when the pressure $\geq 200 \mathrm{MPa}$ and the duration $>30 \mathrm{~min}$. 


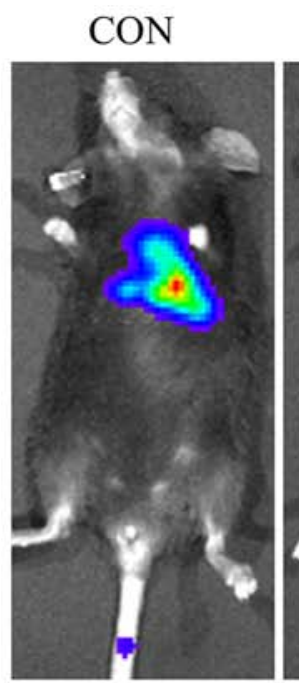

$50 \mathrm{MPa}$
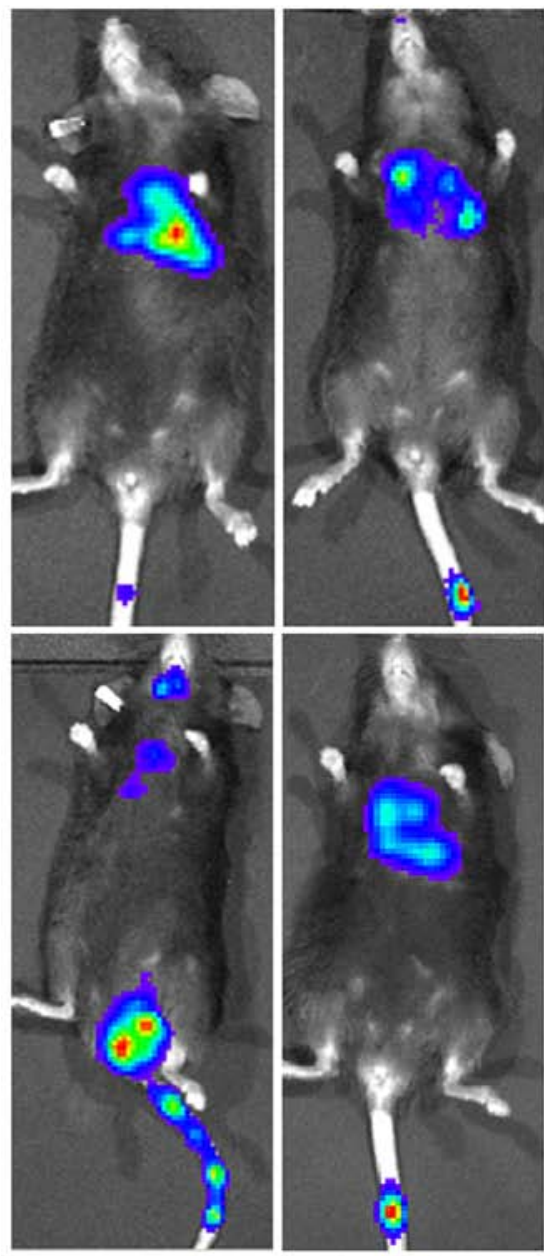

$100 \mathrm{MPa}$
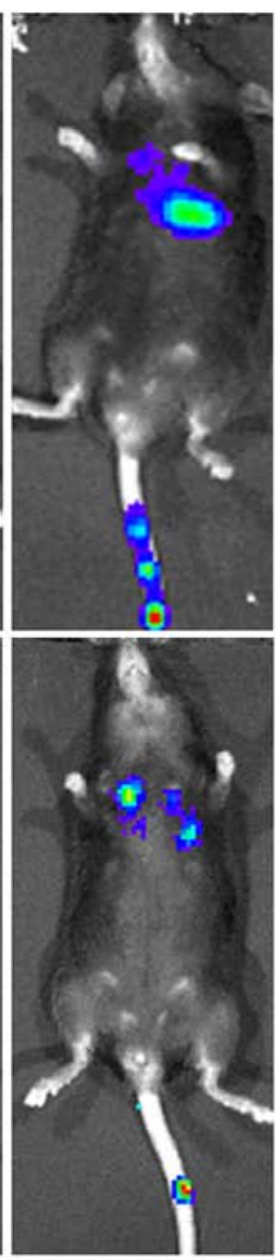

$200 \mathrm{MPa}$
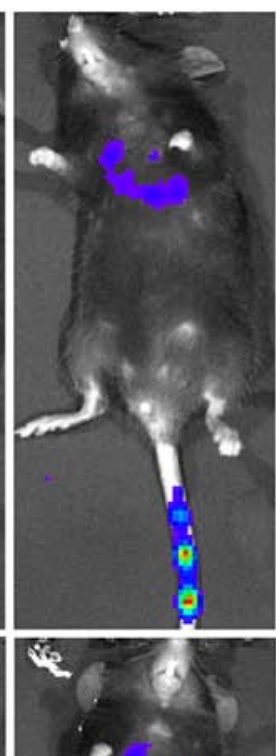

-

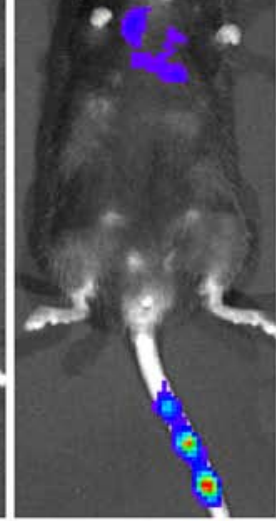

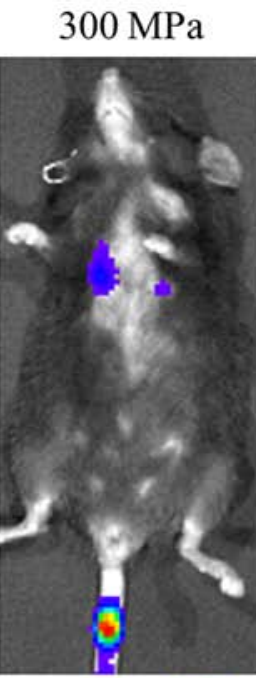

$500 \mathrm{MPa}$
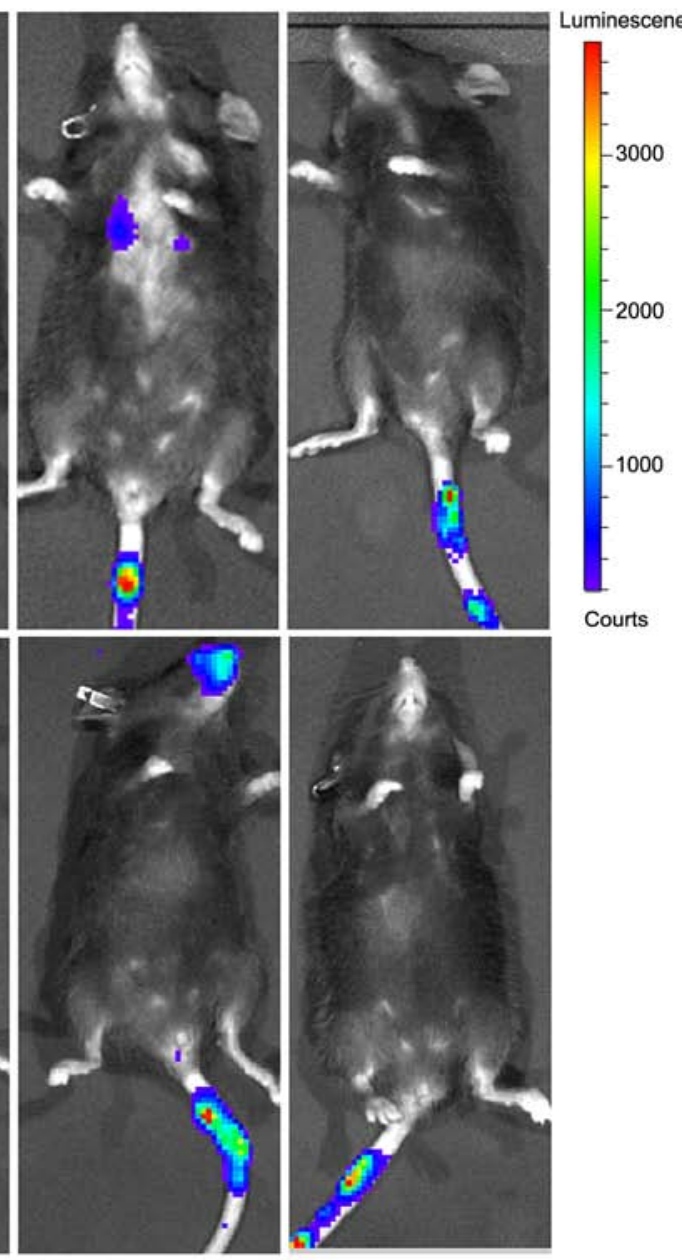

Figure 4. Immunofluorescence in vivo. Images from the group that received $30 \mathrm{~min}$ treatment duration. The immune effect of the $50 \mathrm{MPa}$ group and $100 \mathrm{MPa}$ group were not notably different. The groups of 200,300 and $500 \mathrm{MPa}$, which were compared with the former groups, had significant differences with regards to tumor inhibition.

It has been reported that HHP-treated cancer cells maintain their morphology, even for a number of weeks, and have increased viscosity of the cytoplasm; this feature may be important for an effective vaccine. Furthermore, it was speculated that increased viscosity of the cytoplasm results in a sustained released of relevant cell-derived antigens (49), and these characteristics are important for the immunological effect of malignant cells. Thus, these previous studies support the utility of HHP treatment in the preparation of tumor cells vaccines.

The present results suggest that different pressures and treatment durations may change the final immune efficacy of the vaccine. During HHP treatment, the pressure was distributed throughout the media and the pressure was distributed evenly throughout the experimental samples; it has been reported that the intensity of pressure propagates through all flexible packing materials (50). As every compressed material was given the same pressure quantity, any gradients were mitigated, and thus the effects of HHP could not be attained under the lower pressure ( $<200 \mathrm{MPa})$ and the shorter time ( $<30 \mathrm{~min})$. A previous study demonstrated that vaccination with HHP-killed cancer cells combined with local RTx significantly inhibits tumor growth and improves survival in tumor-bearing mice (51), using a compression time of $300 \mathrm{sec}$. To the best of our knowledge, the present study was the first to test the HHP-treated tumor vaccine efficacy at different compression durations $(1,5,10,30,60$ and $120 \mathrm{~min})$.

In the present study, a sensitive camera with a sufficient exposure time was used to assess the emission of fluorescence from fluorophores in the whole-body living animals, which is known as fluorescence imaging in vivo (52). However, the thick tissue of the mice can absorb and shelter autofluorescence, and thus the equipment may not always receive and collect the fluorescent signals (52); therefore, sufficient exposure time and luciferase are required to complete the test. In the present study fluorescence intensity results suggested that a pressure of $\geq 200 \mathrm{MPa}$ could be used to prepare a vaccine to suppress tumor growth, when the treatment duration was $\geq 30 \mathrm{~min}$.

It was speculated that the technique of HHP may represent an alternative to efficiently develop whole-cell tumor vaccines, when the pressure is $\geq 200 \mathrm{MPa}$ and the treatment duration is $\geq 30 \mathrm{~min}$. The present study not only assessed the effect of different pressures on vaccine efficacy, but also the effect of different pressure durations. Moreover, future work will focus on the immunity mechanism of the vaccination, as well as the optimum pressure and treatment duration in order to optimize 
immune stimulation. However, if the pressure is too high or the duration is too long, this may decrease the immunogenicity of the cancer cells; however, this requires further investigation. Moreover, vaccines are injected multiple times to break the self-tolerance along with the appropriate adjuvants (53). A limitation to the present study was the lack of other assays to assess cell death, the cell cycle and the immunophenotype of the tumor. In addition, there are numerous difficulties that have to be overcome to develop beneficial tumor vaccines. The development of tumor vaccines also has to follow the same standard as radiotherapy and chemotherapy. Collectively, the present study demonstrated a potential production method for tumor-cell vaccines generated via HHP, and this provides a basis for further investigation into the optimization of tumor vaccines.

\section{Acknowledgements}

Not applicable.

\section{Funding}

The present study was supported by Fund of Jilin Provincial Finance Department (grant no. 2018SCZWSZX-010).

\section{Availability of data and materials}

The datasets used and/or analyzed during the current study are available from the corresponding author on reasonable request.

\section{Authors' contributions}

This study was designed and conceived by KL and BL. The experimental procedures and data analysis were carried out by KL, SY, ZM and BL. The manuscript was prepared by KL and BL. All authors read and approved the final manuscript.

\section{Ethics approval and consent to participate}

All animal experiments were conducted according to the National Standard of the Care and Use of Laboratory Animals, and the study was approved by the Animal Ethics Committee of The First Hospital of Jilin University (Approval no. 2019-0456).

\section{Patient consent for publication}

Not applicable.

\section{Competing interests}

The authors declare that they have no competing interests.

\section{References}

1. Jaklitsch MT, Grondin SC and Sugarbaker DJ: Treatment of malignant mesothelioma. World J Surg 25: 210-217, 2001.

2. Spagnolo F, Boutros A, Tanda E and Queirolo P: The adjuvant treatment revolution for high-risk melanoma patients. Semin Cancer Biol 59: 283-289, 2019.
3. Lacy A and O'Kennedy R: Studies on coumarins and coumarinrelated compounds to determine their therapeutic role in the treatment of cancer. Curr Pharm Des 10: 3797-3811, 2004.

4. Spiegel D and Classen C: Group therapy for cancer patients: A research-based handbook of psychosocial care. 1st edition Basic Books, New York, NY, 2000.

5. Hutchison S, Sahay B, de Mello SC, Sayour EJ, Lejeune A, Szivek A, Livaccari AM, Fox-Alvarez S, Salute M, Powers L and Milner RJ: Characterization of myeloid-derived suppressor cells and cytokines GM-CSF, IL-10 and MCP-1 in dogs with malignant melanoma receiving a GD3-based immunotherapy. Vet Immunol Immunopathol 216: 109912, 2019.

6. Indini A, Di Guardo L, Cimminiello C, Prisciandaro M, Randon G, De Braud F and Del Vecchio M: Developing a score system to predict therapeutic outcomes to anti-PD-1 immunotherapy in metastatic melanoma. Tumori 105: 465-473, 2019.

7. Dolan DE and Gupta S: PD-1 pathway inhibitors: Changing the landscape of cancer immunotherapy. Cancer Control 21: 231-237, 2014.

8. Khalil DN, Smith EL, Brentjens RJ and Wolchok JD: The future of cancer treatment: Immunomodulation, CARs and combination immunotherapy. Nat Rev Clin Oncol 13: 273-290, 2016.

9. Li SY, Liu Y, Xu CF, Shen S, Sun R, Du XJ, Xia JX, Zhu YH and Wang J: Restoring anti-tumor functions of $T$ cells via nanoparticle-mediated immune checkpoint modulation. J Control Release 231: 17-28, 2016.

10. Montagne K, Onuma Y, Ito Y, Aiki Y, Furukawa KS and Ushida T: High hydrostatic pressure induces pro-osteoarthritic changes in cartilage precursor cells: A transcriptome analysis. PLoS One 12: e0183226, 2017.

11. Bol KF, Aarntzen EH, Pots JM, Olde Nordkamp MA, van de Rakt MW, Scharenborg NM, de Boer AJ, van Oorschot TG, Croockewit SA, Blokx WA, et al: Prophylactic vaccines are potent activators of monocyte-derived dendritic cells and drive effective anti-tumor responses in melanoma patients at the cost of toxicity. Cancer Immunol Immunother 65: 327-339, 2016.

12. Klippstein R and Pozo D: Nanotechnology-based manipulation of dendritic cells for enhanced immunotherapy strategies. Nanomedicine 6: 523-529, 2010.

13. Schummer V, Flindt S and Hinz T: Tumor vaccines and peptide-loaded dendritic cells (DCs). Bundesgesundheitsblatt Gesundheitsforschung Gesundheitsschutz 58: 1254-1258, 2015 (In German).

14. Gross S, Erdmann M, Haendle I, Voland S, Berger T, Schultz E, Strasser E, Dankerl P, Janka R, Schliep S, et al: Twelve-year survival and immune correlates in dendritic cell-vaccinated melanoma patients. JCI Insight 2: 91438, 2017.

15. Hu Z, Ma Y, Shang Z, Hu S, Liang K, Liang W, Xing X, Wang Y and Du X: Improving immunotherapy for colorectal cancer using dendritic cells combined with anti-programmed death-ligand in vitro. Oncol Lett 15: 5345-5351, 2018.

16. Rosenblatt J and Avigan D: Cellular immunotherapy for multiple myeloma. Best Pract Res Clin Haematol 21: 559-577, 2008.

17. Copier J, Ward S and Dalgleish A: Cell based cancer vaccines: Regulatory and commercial development. Vaccine 25 (Suppl 2): B35S-B46S, 2007.

18. Bliznyuk A, Grossman Y and Moskovitz Y: The effect of high pressure on the NMDA receptor: Molecular dynamics simulations. Sci Rep 9: 10814, 2019.

19. Weiss EM, Meister S, Janko C, Ebel N, Schlücker E, Meyer-Pittroff R, Fietkau R, Herrmann M, Gaipl U and Frey B: High hydrostatic pressure treatment generates inactivated mammalian tumor cells with immunogeneic features. J Immunotoxicol 7: 194-204, 2010.

20. Franco I, Castillo E, Perez MD, Calvo M and Sanchez L: Effects of hydrostatic high pressure on the structure and antibacterial activity of recombinant human lactoferrin from transgenic rice. Biosci Biotechnol Biochem 76: 53-59, 2012.

21. Zhang Y, Dai B, Deng Y and Zhao Y: In vitro anti-inflammatory and antioxidant activities and protein quality of high hydrostatic pressure treated squids (Todarodes pacificus). Food Chem 203: 258-266, 2016.

22. Chen H, Xiao G, Xu Y, Yu Y, Wu J and Zou B: High hydrostatic pressure and Co-fermentation by lactobacillus rhamnosus and gluconacetobacter xylinus improve flavor of yacon-litchi-longan juice. Foods 8: E308, 2019.

23. Woo HJ, Park JB, Kang JH, Chun HH and Song KB: Combined treatment of high hydrostatic pressure and cationic surfactant washing to inactivate listeria monocytogenes on fresh-cut broccoli. J Microbiol Biotechnol 29: 1240-1247, 2019. 
24. Yamamoto K: Food processing by high hydrostatic pressure. Biosci Biotechnol Biochem 81: 672-679, 2017.

25. Huang R, Ye M, Li X, Ji L, Karwe M and Chen H: Evaluation of high hydrostatic pressure inactivation of human norovirus on strawberries, blueberries, raspberries and in their purees. Int J Food Microbiol 223: 17-24, 2016.

26. Diehl P, Schauwecker J, Mittelmeier W and Schmitt M: High hydrostatic pressure, a novel approach in orthopedic surgical oncology to disinfect bone, tendons and cartilage. Anticancer Res 28: 3877-3883, 2008

27. Barnes CA, Robertson AJ, Louis JM, Anfinrud P and Bax A: Observation of $\beta$-amyloid peptide oligomerization by pressure-jump NMR spectroscopy. J Am Chem Soc 141: 13762-13766, 2019.

28. Shearer AE and Kniel KE: High hydrostatic pressure for development of vaccines. J Food Prot 72: 1500-1508, 2009

29. Golub M, Lehofer B, Martinez N, Ollivier J, Kohlbrecher J, Prassl R and Peters J: High hydrostatic pressure specifically affects molecular dynamics and shape of low-density lipoprotein particles. Sci Rep 7: 46034, 2017.

30. Winter R and Dzwolak W: Temperature-pressure configurational landscape of lipid bilayers and proteins. Cell Mol Biol (Noisy-le-grand) 50: 397-417, 2004.

31. Winter R: Synchrotron X-ray and neutron small-angle scattering of lyotropic lipid mesophases, model biomembranes and proteins in solution at high pressure. Biochim Biophys Acta 1595: $160-184,2002$.

32. National Research Council (US) Committee for the Update of the Guide for the Care and Use of Laboratory Animals: Guide for the Care and Use of Laboratory Animals. National Academies Press (US), Washington, DC, 2011.

33. Varela A, Salagianni M, Galani I, Andreakos E and Davos CH: The role of TLR7 receptors on cardiac and vascular function of ApoE-/-mice. Eur J Echocardiography 12 (Suppl 2): P757, 2011.

34. Leary SL, Underwood W, Anthony R, Cartner S, Corey D, Grandin T, Greenacre C, Gwaltney-Bran S, McCrackin M and Meyer R (eds): AVMA guidelines for the euthanasia of animals: 2013 edition. American Veterinary Medical Association Schaumburg, IL, 2013.

35. Zhuang X, Wu T, Zhao Y, Hu X, Bao Y, Guo Y, Song Q, Li G, Tan S and Zhang Z: Lipid-enveloped zinc phosphate hybrid nanoparticles for codelivery of $\mathrm{H}-2 \mathrm{~K}$ b and $\mathrm{H}-2 \mathrm{D}$ b-restricted antigenic peptides and monophosphoryl lipid A to induce antitumor immunity against melanoma. J Control Release 228: 26-37, 2016.

36. De Gruijl TD, van den Eertwegh AJ, Pinedo HM and Scheper RJ: Whole-cell cancer vaccination: From autologous to allogeneic tumor-and dendritic cell-based vaccines. Cancer Immunol Immunother 57: 1569-1577, 2008.

37. Frey B, Schildkopf P, Rödel F, Weiss EM, Munoz LE, Herrmann M, Fietkau R and Gaipl US: AnnexinA5 renders dead tumor cells immunogenic-implications for multimodal cance therapies. J Immunotoxicol 6: 209-216, 2009.

38. Estrela-Llopis VR, Chevichalova AV, Tregubova NA, Shishko ED and Litvin PM: Platinum nanoparticles with adsorptive layer of Chlorella vulgaris polysaccharides inactivate tumor cells of ascitic ehrlich carcinoma, ovarian cancer and leukemia. In: Nanocomposites, nanophotonics, nanobiotechnology, and applications. Fesenko O and Yatsenko L (eds). Vol 156. Springer Proceedings in Physics, Springer, Cham, 2015.

39. Hollingsworth RE and Jansen K: Turning the corner on therapeutic cancer vaccines. NPJ Vaccines 4: 7, 2019.
40. Kepp O, Tesniere A, Schlemmer F, Michaud M, Senovilla L, Zitvogel L and Kroemer G: Immunogenic cell death modalities and their impact on cancer treatment. Apoptosis 14: 364-375, 2009.

41. Melief CJM, van Hall T, Arens R, Ossendorp F and van der Burg SH: Therapeutic cancer vaccines. J Clin Invest 125 : 3401-3412, 2015.

42. Gross M and Jaenicke R: Proteins under pressure: The influence of high hydrostatic pressure on structure, function and assembly of proteins and protein complexes. Eur J Biochem 221: 617-630, 1994.

43. Urbanova L, Hradilova N, Moserova I, Vosahlikova S, Sadilkova L, Hensler M, Spisek R and Adkins I: High hydrostatic pressure affects antigenic pool in tumor cells: Implication for dendritic cell-based cancer immunotherapy. Immunol Lett 187: 27-34, 2017

44. Fucikova J, Moserova I, Truxova I, Hermanova I, Vancurova I, Partlova S, Fialova A, Sojka L, Cartron PF, Houska M, et al: High hydrostatic pressure induces immunogenic cell death in human tumor cells. Int J Cancer 135: 1165-1177, 2014.

45. Weiss EM, Wunderlich R, Ebel N, Rubner Y, Schlücker E, Meyer-Pittroff R, Ott OJ, Fietkau R, Gaipl US and Frey B: Selected anti-tumor vaccines merit a place in multimodal tumor therapies. Front Oncol 2: 132, 2012.

46. Gaipl US, Munoz LE, Rödel F, Pausch F, Frey B, Brachvogel B, von der Mark K and Pöschl E: Modulation of the immune system by dying cells and the phosphatidylserine-ligand annexin A5. Autoimmunity 40: 254-259, 2007.

47. Boonyaratanakornkit BB, Park $\mathrm{CB}$ and Clark DS: Pressure effects on intra-and intermolecular interactions within proteins. Biochim Biophys Acta 1595: 235-249, 2002.

48. Korn A, Frey B, Sheriff A, Gaipl U, Franz S, Meyer-Pittroff R, Bluemelhuber $\mathrm{G}$ and Herrmann M: High hydrostatic pressure inactivated human tumour cells preserve their immunogenicity. Cell Mol Biol (Noisy-le-grand) 50: 469-477, 2004

49. Frey B, Franz S, Sheriff A, Korn A, Bluemelhuber G, Gaipl U, Voll R, Meyer-Pittroff R and Herrmann M: Hydrostatic pressure induced death of mammalian cells engages pathways related to apoptosis or necrosis. Cell Mol Biol (Noisy-le-grand) 50: 459-467, 2004.

50. Patterson MF: Microbiology of pressure-treated foods. J Appl Microbiol 98: 1400-1409, 2005.

51. Seitz C, Rückert M, Deloch L, Weiss EM, Utz S, Izydor M, Ebel N, Schlücker E, Fietkau R, Gaipl US and Frey B: Tumor cell-based vaccine generated with high hydrostatic pressure synergizes with radiotherapy by generating a favorable anti-tumor immune microenvironment. Front Oncol 9: 805, 2019.

52. Rao J, Dragulescu-Andrasi A and Yao H: Fluorescence imaging in vivo: Recent advances. Curr Opin Biotechnol 18: 17-25, 2007.

53. Chang EY, Chen CH, Ji H, Wang TL, Hung K, Lee BP, Huang AY, Kurman RJ, Pardoll DM and Wu T: Antigen-specific cancer immunotherapy using a GM-CSF secreting allogeneic tumor cell-based vaccine. Int J Cancer 86: 725-730, 2000.

This work is licensed under a Creative Commons Attribution-NonCommercial-NoDerivatives 4.0 International (CC BY-NC-ND 4.0) License. 